\title{
Tailoring mesoporosity of poly(furfuryl alcohol)-based activated carbons and their ability to adsorb organic compounds from water
}

\author{
Ewa Lorenc-Grabowska ${ }^{1} \cdot$ Piotr Rutkowski $^{1}$
}

Received: 1 November 2017 / Accepted: 28 March 2018 / Published online: 11 April 2018

(c) The Author(s) 2018

\begin{abstract}
In this work it was shown that polymers can be recycled into a promising adsorbent for organic dyes and phenols waste removal. For this, a series of activated carbons (ACs) were produced from mixture of ferrocene or titanium acetylacetonate with poly(furfuryl alcohol) (PFA) by steam activation. The introduction of ferrocene as Fe precursor was found to be an efficient catalyst in mesoporosity development during carbonization and subsequent steam activation at $850{ }^{\circ} \mathrm{C}$, whereas the polymer based only and titanium-doped ACs are typically microporous. The porous structure parameters were determined from nitrogen adsorption isotherms measured at $77 \mathrm{~K}$. Scanning electron microscopy was applied to monitor the metal distribution of metal-loaded char and the surface morphology of activated carbons. The adsorption capacity was found to be dependent mainly on pore size distribution. In the case of phenol adsorption, the adsorption was defined by volume of pore with size $0.8-1.4 \mathrm{~nm}$; whereas, for Congo red best fit was observed for volume of pore with size $2-5 \mathrm{~nm}$.
\end{abstract}

Keywords Poly(furfuryl alcohol) $\cdot$ Gasification $\cdot$ Metal catalyst $\cdot$ Phenol $\cdot$ Congo red

\section{Introduction}

The constant development of civilization leads to expansion of problems related to municipal solid waste management. The problems deal not only with collection, transport, processing or storage, but also with the disposal of waste and secondary pollution of landfill. An interesting concept of reducing the waste is the production of activated carbons (ACs) from solid waste. It allows to utilize the waste and the obtained adsorbent can be used for further environment protection. The solid organics with relatively high content of organic matter including plastic bottles, agricultural or food waste like straw, rice hull, seeds or fruits shells are some examples of raw waste materials that can be used to produce activated carbons [1-3]. The ACs can be produced by both physical and chemical activation. The physical activation of waste biomass or polymers usually gives activated carbon with well-developed microporosity and surface are in range of $400-1100 \mathrm{~m}^{2} \mathrm{~g}^{-1}[1,2]$. The chemical activation results

Ewa Lorenc-Grabowska

ewa.lorenc-grabowska@pwr.edu.pl

1 Department of Polymer and Carbonaceous Materials, Faculty of Chemistry, Wrocław University of Science and Technology, Gdańska 7/9, 50-344 Wrocław, Poland in visibly larger surface area usually higher than $1500 \mathrm{~m}^{2} \mathrm{~g}^{-1}$ $[1,2]$.

Activated carbons (ACs) with specific porous texture have been of subject of broad interest for many years. There are many application areas, among them dyes, vitamins, polymer and bio-molecules adsorption as well as catalyst preparation, which require well-developed mesoporosity of carbon material [4]. Activated carbons considered as catalyst carrier, material for hydrogen or methane storage or electrode material for electric double-layer capacitors or supercapacitors should also be characterized by high contribution of mesopores [5-7].

The mesoporous ACs might be prepared in several ways, i.e., by carbonization and activation of proper carbonaceous precursor or the sol-gel process and the template method [8-11]. Another efficient way for mesoporosity development is the catalytic gasification [9-18]. The different metals and different forms of the same metal have different catalytic effects on the gasification of carbonaceous materials. Generally it is assumed that metal particles gasify carbon in their immediate vicinity and create the porosity by forming holes in the carbon matrix. Transition metal and alkali earth metals have been recognized as good catalysts for the gasification of carbon materials to produce activated carbons with developed meso- and 
macroporosity [9-11]. Activated carbon with a remarkable contribution of mesopores by steam activation of different rank coals containing small amounts of metal ( $\mathrm{Y}, \mathrm{Al}$, $\mathrm{Ti}, \mathrm{Zr}$ ) acetylacetonate has been known [12]. Similarly calcium or iron have been recognized as effective catalysts for carbon gasification, promoting the mesopore formation [14]. Iron is one of the metals commonly used in mesopore formation [14-18]. A different form of $\mathrm{Fe}$ has been used to produce the ACs with developed mesoporosity. The ferrocene was found to be very efficient in mesoporosity development in pitch $[16,18]$. Ferrocene was also used to introduce iron into the PFA but no details about the porosity development were given [19]. What is more, iron on activated carbons can be also used as catalyst in catalytic degradation of polypropylene [20].

In recent years there has been a strong emphasis on the production of ACs from waste products, including waste polymers and agricultural by-products. Poly(furfuryl alcohol), (PFA) is an interesting low-cost precursor for preparing ACs due to its high yield of solid residue of carbonization. PFA is a thermally cross-linked polymer synthesized from furfuryl alcohol (FA). Furfuryl alcohol can be derived from waste carbohydrate-rich biomass resources. The PFA is compatible with many organic polymers and inorganic materials therefore it has been not only important for the use as adhesive and binder, but also is widely used to synthesize nanoporous carbons, glassy carbons and polymers nanocomposites. The ACs produced by physical and chemical activations of PFA are predominantly microporous [21-23], however PFA has been also used as carbon precursor for producing mesoporous ACs by template method [8]. The PFA is also found as good precursor for molecular sieve carbons production were it is used as carbon sources [24-26]. According to Burkat et al. [23] upon pyrolysis up to $300{ }^{\circ} \mathrm{C}$, PFA spontaneously decomposes and converts to a solid with well-developed both micro- and mesoporosity. However, as the pyrolysis temperature increases, the mesoporosity disappears and only microporosity is retained. The mesoporosity development in PFA was observed for ferrocene doped PFA. The mesoporosity formation in the obtained char was explained on the basis of disordered nanoshells [27]. It should be, however, emphasized that the obtained material was characterized by rather low surface area.

This work had dual object. The first one was to convert the polymer into a useful adsorbent. In order to obtain the desired property of adsorbents, the porosity in PFA-based ACs was tailored by steam activation of iron- or titaniumcontaining PFA. The influence of metal on the gasification process of PFA has been studied. The second aim was to elucidate the utility of such polymer-based adsorbent for the efficient removal of different water contaminations. For that, among the resultant ACs, the $\mathrm{AC}$ of the highest mesopore volume was selected to study the adsorption of dyes from aqueous solution, whereas the microporous ACs have been selected to phenol adsorption studies.

The adsorbents obtained in this work are characterized by neutral surface characteristic that is crucial in the case of adsorption from aqueous solvent as it eliminates the competition effect for active sites between adsorbates and water. What is more, it shows that the adsorption capacity of phenol and Congo red on neutral adsorbent is dependent on the volume of pore with defined pore width. Hence tailoring of the porosity of waste material by gasification in the presence of a catalyst has proved to be a cheap and efficient way of recycling polymeric waste.

\section{Materials and methods}

\section{Adsorbents preparation}

Poly(furfuryl alcohol) (PFA) synthesis: $100 \mathrm{~cm}^{3} \mathrm{~g}^{-1}$ of furfuryl alcohol was mixed with $0.60 \mathrm{~cm}^{3} \mathrm{~g}^{-1}$ of concentrated hydrochloric acid. The mixture of PFA and metal was prepared as follow: $100 \mathrm{~cm}^{3} \mathrm{~g}^{-1}$ of furfuryl alcohol was mixed with ferrocene/titanium acetylacetonate and next $0.60 \mathrm{~cm}^{3} \mathrm{~g}^{-1}$ of concentrated hydrochloric acid was added. Naming of samples: polymer containing $0.15 \% \mathrm{wt} \%$ of iron, on the basis of metal content to the resultant polymer (PFA/Fe/0.15) or $0.5 \mathrm{wt} \%$ of titanium (PFA/Ti/0.5) was prepared. All polymers were dried at $85{ }^{\circ} \mathrm{C}$ for $20 \mathrm{~h}$ and next for $20 \mathrm{~h}$ at $140{ }^{\circ} \mathrm{C}$. The polymers were pulverized into particles smaller than $0.5 \mathrm{~mm}$. The samples were carbonized at a heating rate of $10{ }^{\circ} \mathrm{C}$ at $900{ }^{\circ} \mathrm{C}$ for $1 \mathrm{~h}$, in a horizontal oven, in a nitrogen atmosphere. The obtained char was steam activated at $850{ }^{\circ} \mathrm{C}$ up to $50 \%$ of burn off.

\section{Characterization of the ACs}

The elemental analysis for $\mathrm{C}, \mathrm{H}, \mathrm{N}$ and $\mathrm{S}$ was performed using a Vario III Elemental Analyzer. The oxygen content was calculated by difference. The porous texture was determined from nitrogen adsorption isotherms measured at $77 \mathrm{~K}$ on a NOVA 2200 (Quantachrome) device. The data were analyzed to obtain: (1) the specific surface area using the BET method at $p / p_{0}<0.15\left(S_{\mathrm{BET}}\right)$; (2) the amount of nitrogen adsorbed at a relative pressure $\left(p / p_{0}\right)$ of 0.98 in order to determine the total pore volume $\left(V_{\mathrm{T}}\right)$; (3) the micropore volume by applying the Dubinin-Radushkevich equation up to $p / p_{0}, 0.15\left(V_{\mathrm{DR}}\right)$; (4) the mesopore volume $\left(V_{\mathrm{mez}}\right)$ calculated as the difference between the $V_{\mathrm{T}}$ and $V_{\mathrm{DR}}$; and (5) the pore size distribution (PSD) in terms of microporosity by means of the density functional theory (DFT) method using Nova Quantachrome software and the Kelvin equation for mesoporosity. The $\mathrm{pH}_{\mathrm{PZC}}$ (point of zero charge) of the ACs was determined by mixing $1 \mathrm{~g}$ of each $\mathrm{AC}$ with 
$20 \mathrm{ml}$ of $\mathrm{CO}_{2}$-free distilled water, according to the procedure described by Moreno-Castilla et al. [28].

Scanning electron microscopy (SEM) images of the electrode material were obtained on an EVO LS13 Zeiss scanning electron microscope. The reactivity of char was calculated according to Eq. (1):

$R=\Delta m /\left(m_{0} t\right)$,

where $\Delta m$ is the loss of weight $(\mathrm{g}), m_{0}$ is the initial mass of a char $(\mathrm{g})$ and $t$ is the activation time $(\mathrm{h})$.

\section{Adsorption of phenol and Congo red}

The application of ACs for water purification requires adsorbents with specific characteristics. The adsorption of Congo red $(\mathrm{CR})$ and phenol $(P)$ from aqueous solutions was carried out at $24{ }^{\circ} \mathrm{C}$ in a static system. For the adsorption, 0.01-0.2 g of $\mathrm{AC}$ was placed into Erlenmeyer flasks and $0.10 \mathrm{dm}^{3}$ of adsorbate solution $50 \mathrm{mg} \mathrm{dm}^{-3}$ for $\mathrm{CR}$ and $150 \mathrm{mg} \mathrm{cm}^{-3}$ for $P$ was added to each flask. The stoppered flasks were kept in a thermostat shaker bath and were agitated to reach equilibrium. Each set of flasks included two flasks containing blank solutions to check for sorbate volatilization and adsorption on the glass walls. The adsorption isotherms were determined without adding any buffer to control $\mathrm{pH}$ to avoid

Table 1 Phenol and Congo red physicochemical characteristics

\begin{tabular}{lll}
\hline & Phenol $(P)$ & Congo red (CR) \\
\hline Molar mass $\left(\mathrm{g} \mathrm{mol}^{-1}\right)$ & 94.11 & 650.73 \\
Solubility $\left(\mathrm{g} \mathrm{dm}^{-3}\right)$ & 80 & 25 \\
$\mathrm{pK}_{\mathrm{a}}$ & 9.98 & 5.50 \\
Molecular volume $\left(\mathrm{nm}^{3} \mathrm{~mol}^{-3}\right)$ & 89 & 422.9 \\
Molecular dimension & & \\
Width (nm) & 0.57 & 2.62 \\
Depth $(\mathrm{nm})$ & 0.43 & 0.74 \\
Thickness $(\mathrm{nm})$ & - & 0.43 \\
\hline
\end{tabular}

the presence of a new electrolyte in the system. The solution $\mathrm{pH}$ was measured by a digital $\mathrm{pH}$-meter (Accumet Basic, Fisher Scientific) using a glass electrode. The concentration of each solute remaining in the water phase was quantified. The phenol concentration was determined using HITACHI U-2800A UV-Vis spectrophotometer at the wavelength of 485 and $280 \mathrm{~nm}$. Table 1 presents the basic characteristics of adsorbates used in this work.

\section{Results and discussion}

\section{Tailoring micro-mesoporosity in PFA-based ACs}

Usually the thermal conversion of polymer gives a material with low porosity and the further physical activation process develops the microporosity. In the case of adsorption from water, due to the molecular size of the contamination, an adsorbent with both micro- and mesoporosity is required for the process to proceed efficiently. In this work, the process of tailoring the porous texture in polymer-based adsorbents have been obtained by pyrolysis of mixtures of polymer and metal complexes. This approach, compared to metal loading on the surface by impregnation, allows to introduce active sites both in the bulk and on the surface of the material. Table 2 and Fig. 1 present the characteristic of pyrolysis and activation processes. It can be observed that type of metal and its content, introduced into the polymer, has no effect on carbonization processes (Table 2), but a significant influence on activation and char reactivity was observed (Fig. 1). The yield of pyrolysis process is quite high between 46.7 and $50 \%$, and varies insignificantly for all samples despite the metal type or metal amount. On the contrary, the reactivity of the samples changes remarkably. It can be seen that the presence of iron changes the reactivity of char to a very high extent from $0.22 \mathrm{~h}^{-1}$ up to $1.80 \mathrm{~h}^{-1}$ (Fig. 1). Nevertheless, the increase in iron content is not followed by constant increase is reactivity of char, as the highest reactivity of
Table 2 Basic characteristics of the studied activated carbons

\begin{tabular}{|c|c|c|c|c|}
\hline \multirow[t]{2}{*}{ Sample name } & \multirow{2}{*}{$\begin{array}{l}\text { Carbonization yield } \\
\text { (wt\%) }\end{array}$} & \multicolumn{3}{|c|}{ Porous texture parameters } \\
\hline & & $V_{\text {mic }}\left(\mathrm{cm}^{3} \mathrm{~g}^{-1}\right)$ & $V_{\mathrm{mez}}\left(\mathrm{cm}^{3} \mathrm{~g}^{-1}\right)$ & $S_{\mathrm{BET}}\left(\mathrm{m}^{2} \mathrm{~g}^{-1}\right)$ \\
\hline PFA & 47.9 & 0.505 & 0.103 & 1308 \\
\hline $\mathrm{PFA} / \mathrm{Fe} / 0.1$ & 47.9 & 0.363 & 0.212 & 971 \\
\hline $\mathrm{PFA} / \mathrm{Fe} / 0.2$ & 46.8 & 0.153 & 0.449 & 394 \\
\hline $\mathrm{PFA} / \mathrm{Fe} / 0.3$ & 47.2 & 0.148 & 0.536 & 410 \\
\hline $\mathrm{PFA} / \mathrm{Fe} / 0.35$ & 49.5 & 0.152 & 0.523 & 400 \\
\hline $\mathrm{PFA} / \mathrm{Fe} / 0.45$ & 49.0 & 0.145 & 0.490 & 371 \\
\hline $\mathrm{PFA} / \mathrm{Fe} / 0.5$ & 47.4 & 0.136 & 0.542 & 411 \\
\hline PFA/Ti/0.1 & 50.0 & 0.506 & 0.121 & 1245 \\
\hline PFA/Ti/0.3 & 47.5 & 0.376 & 0.062 & 1035 \\
\hline PFA/Ti/0.5 & 46.7 & 0.415 & 0.087 & 1057 \\
\hline
\end{tabular}




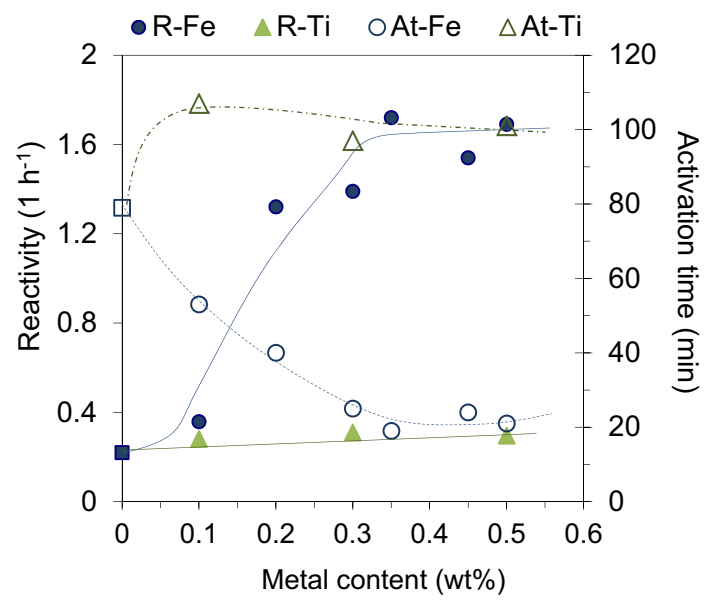

Fig. 1 Relationships between the metal content in PFA and the char reactivity (filled) and activation time (empty)

char is found for PFA/Fe/0.35 not for PFA/Fe/0.5. Only a slight increase in char reactivity is observed in the case of Ti-doped samples $\left(0.22-0.31 \mathrm{~h}^{-1}\right)$. The high reactivity is very desirable as it can reduce the time and energy needed to conduct the processes of polymer conversion. The presence of metal has a pronounced effect on activation time. In the case of iron-loaded samples the activation time decreases from 79 min for PFA up to $19 \mathrm{~min}$ for PFA/Fe/0.35. Again the further increase in iron content does not have any positive effect on the activation time. Contrary to iron, titanium prolonged the activation time about $20 \mathrm{~min}$.

Both metals used in this work are considered as catalysts promoting mesopore development [10-12 14, 16, 26]. One can observe in Fig. 2 that the presence of iron changes the porous texture of the resultant ACs to a high extent. The catalytic activity of $\mathrm{Fe}$ to form mesopores is apparent. A small amount of $\mathrm{Fe}$ (PFA/Fe/0.1) develops mainly small mesopores with a width of $2-5 \mathrm{~nm}$, whereas a further increase in iron content leads to the formation of larger mesopores. The pore volume of mesopores with a width of 10-50 nm increases up to sevenfold compared to PFA charderived AC, from 0.06 to $0.417 \mathrm{~cm}^{3} \mathrm{~g}^{-1}$. With increasing the Fe content up to $0.2 \mathrm{wt} \%$, a reasonable decrease in the micropore volume can be observed. However for activated carbon obtained from PFA doped with a higher amount of Fe (above $0.2 \mathrm{wt} \%$ ) the micropore volume remains on the same level. As shown in Fig. 2, an increase in the mesopore volume is followed by an increase in the total pore volume when the Fe content in PFA is higher than $0.2 \mathrm{wt} \%$. Doping PFA with $\mathrm{Fe}$ results in a decrease of BET surface area of the resultant ACs, from 1306 for PFA to about $400 \mathrm{~m}^{2} \mathrm{~g}^{-1}$, when the Fe content in PFA is $0.2 \mathrm{wt} \%$ and higher. Contrary to iron, titanium is completely inactive in porosity development. The PFA/Ti/0.1 has porous texture parameters comparable with PFA, but a further increase in titanium content caused the collapse in porosity development. The $\mathrm{S}_{\mathrm{BET}}$ decreased to approximately $1000 \mathrm{~m}^{2} \mathrm{~g}^{-1}$ and similarly micropore and mesopore volumes. Figure 3 gives the SEM images of PFA/Fe/0.35 (Fig. 3a) and PFA/Ti/0.1 (Fig. 3b). As can be seen the surface of the obtained carbons varies significantly. In the case of PFA/Fe, we can observe the "glassy" surface with holes, whereas for the PFA/Ti carbon the surface is not smooth and contains many fissures and cavernous regions.

According to Tamai et al. [11] and Yoshizawa et al. [12] the formation of mesoporosity in the activated carbon produced from $\mathrm{Ti}(\mathrm{acac})_{2}$ impregnated coal is closely related to the migration of $\mathrm{TiO}_{2}$ from the carbon matrix $[15,16]$. Due to the fact that the cross-linking forms between the polymer backbone leaving the polymer highly conjugated, the $\mathrm{TiO}_{2}$ particles are unable to migrate in the PFA matrix. In the case of iron, the mesopore development is explained by the gasification of the carbon matrix in the proximity of the $\mathrm{Fe}$ particles. The extent to which a catalyst accelerates carbon gasification, leading to the mesopore generation, is a complex function of many variables, including the size of the
Fig. 2 Pore size distribution of PFA-based ACs determined by Kelvin method

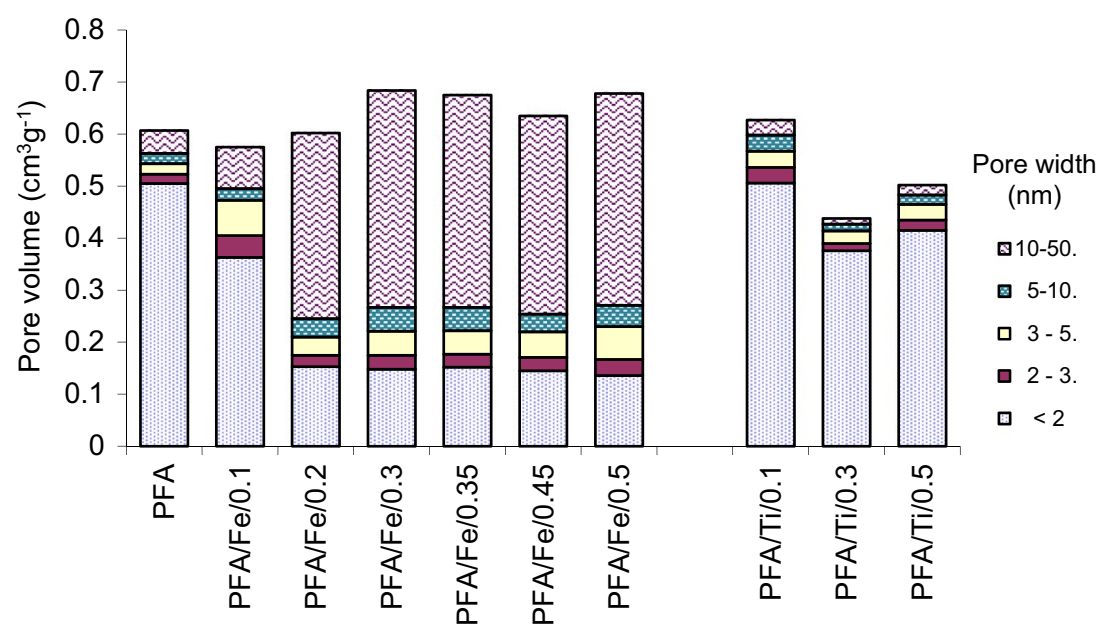



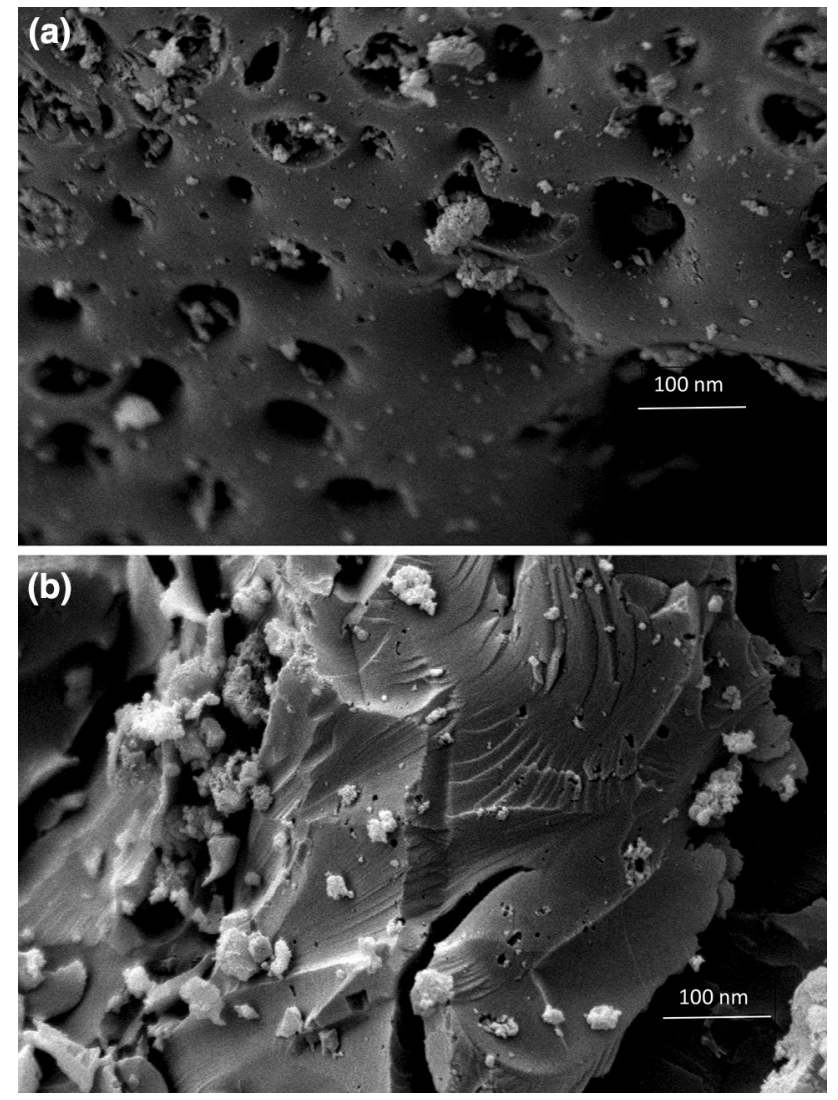

Fig. 3 SEM images for chars: a PFA/Fe/0.3; b PFA/Ti/0.1

catalyst particles, their dispersion degree throughout the carbon matrix, the chemical state of the catalyst and the amount of the catalyst $[12,13]$. It was reported that a small amount of iron is insufficient to develop mesopores; whereas on the contrary, iron surplus can decrease its catalytic activity due to the aggregation of the catalyst particle [12]. The steam activation of iron-loaded PFA expands the porous texture as was presented in this work; however, the development stops when iron content increase above the $0.3 \mathrm{wt} \%$.

The carbonization temperature changes the chemical form of iron but does not change the particle size [18]. Hence it can be assumed that at the same carbonization temperature iron is in the same form and hence the only difference between the PFA/Fe/0.3 and PFA/Fe/0.5 is the amount of iron particles introduced. During steam activation iron catalyzes the gasification in the closest neighborhood of iron particle by making a hole in the carbon matrix. The catalyst particle "attacks" the basal plane, thus forming holes. This can continue to increase in depth due to the penetration of catalyst and can also expand due to the edge recession of the hole [17]. In this way, iron particles migrate and meet with each other, suffering the sintering and the agglomeration [18]. The higher iron content forces the particles to meet more frequently, leading to a stronger sintering and agglomeration effect, causing a loss or decrease in catalytic activity. On the contrary, small iron content $(0.1 \mathrm{wt} \%)$ is insufficient to form well-developed mesoporous material. Based on that, an optimum of iron content has to be established. In present work we can observe that the highest reactivity and biggest mesopore volume is found for material loaded with $0.3 \mathrm{wt} \%$ of iron hence this can be considered as the optimum. It should be emphasized that the observed iron agglomerates are in size around $25 \mathrm{~nm}$. Hence based on the fact that the gasification mainly appears in close neighborhood of the catalyst particles, the pores formed are in size close to the agglomerates. This explains why mainly pore with size $10-50 \mathrm{~nm}$ are developed.

In order to study if iron is indeed in the matrix or only on the surface, the PFA/Fe/0.5 activated carbon was treated with concentrated hydrochloric acid. The ash content decreased from 0.87 to $0.34 \mathrm{wt} \%$. The remaining ash shows that some of iron particles are not accessible. This is due to the fact that they are in the carbon matrix.

The study shows that the introduction of small amount of different metals allows changing the polymer reactivity toward carbonization and activation processes as well as tailoring the porous texture of adsorbent produced from that polymer.

\section{Characterization of PFA-based ACs used for adsorption tests}

The PFA, PFA/Fe/0.3 and PFA/Ti/0.1 were selected for the adsorption tests. These ACs were additionally characterized in terms of elemental composition, pHPZC (Table 3) and micropore size distribution by the DFT method (Fig. 4). The AC produced from $0.3 \mathrm{wt} \% \mathrm{Fe}$-containing PFA is characterized by the highest mesoporosity $\left(\mathrm{Vmez}=0.536 \mathrm{~cm}^{3} \mathrm{~g}^{-1}\right.$, $\mathrm{Vmez} / \mathrm{VT}=0.83$ ) of all the prepared ACs. As can be seen, the metal-loaded adsorbents have well-developed ultramicroporosity; an optimum of pore volume at the $0.6 \mathrm{~nm}$ width is observed. Nevertheless, the volume of ultramicropores is much higher for the PFA/Ti/0.1 carbon, whereas the PFA/ $\mathrm{Fe} / 0.3$ has bigger volume of small mesopores. The maximum of micropore size distribution (MSD) in the case of PFA is shifted to bigger micropore and is observed at pore width of $1.2 \mathrm{~nm}$. Although the volume of micropore for the PFA and PFA/Ti/0.1 (Table 2) is comparable, the MSD is completely different.

In the case of adsorption from water, the surface characteristics as well as the porous texture are considered as very important factors [29-32]. The surface characteristic is governed by the heteroatom presented on the surface in form of functional groups. The heteroatoms that are considered as important in adsorption processes from water are oxygen and nitrogen. As can be seen (Table 3 ) the $\mathrm{O}+\mathrm{N}$ content in PFA is very low. Twofold higher oxygen content is found in 
Table 3 Basic characteristics of activated carbons used for adsorption tests

\begin{tabular}{|c|c|c|c|c|c|c|c|c|c|c|c|}
\hline \multirow[t]{2}{*}{ Sample name } & \multirow{2}{*}{$\begin{array}{l}\text { Ash } \\
\text { content } \\
\text { (wt } \%)\end{array}$} & \multirow[t]{2}{*}{$\mathrm{pH}_{\mathrm{PZC}}$} & \multicolumn{5}{|c|}{$\begin{array}{l}\text { Ultimate analysis (wt\%, dry, } \\
\text { ash-free basis) }\end{array}$} & \multicolumn{4}{|c|}{$\begin{array}{l}\text { PSD based on Kelvin equation } \\
\left(\mathrm{cm}^{3} \mathrm{~g}^{-1}\right)\end{array}$} \\
\hline & & & $\mathrm{C}$ & $\mathrm{H}$ & $\mathrm{N}$ & $\mathrm{S}$ & $\mathrm{O}$ & $2-3 \mathrm{~nm}$ & $3-5 \mathrm{~nm}$ & $5-10 \mathrm{~nm}$ & $10-50 \mathrm{~nm}$ \\
\hline PFA & 0.00 & 7.6 & 97.08 & 1.30 & 0.03 & 0.01 & 1.58 & 0.018 & 0.020 & 0.020 & 0.064 \\
\hline $\mathrm{PFA} / \mathrm{Fe} / 0.3$ & 0.83 & 7.8 & 95.55 & 0.38 & 0.08 & 0.00 & 3.98 & 0.031 & 0.063 & 0.041 & 0.407 \\
\hline PFA/Ti/0.1 & 2.31 & 7.3 & 96.12 & 0.41 & 0.01 & 0.00 & 3.46 & 0.030 & 0.031 & 0.031 & 0.029 \\
\hline
\end{tabular}

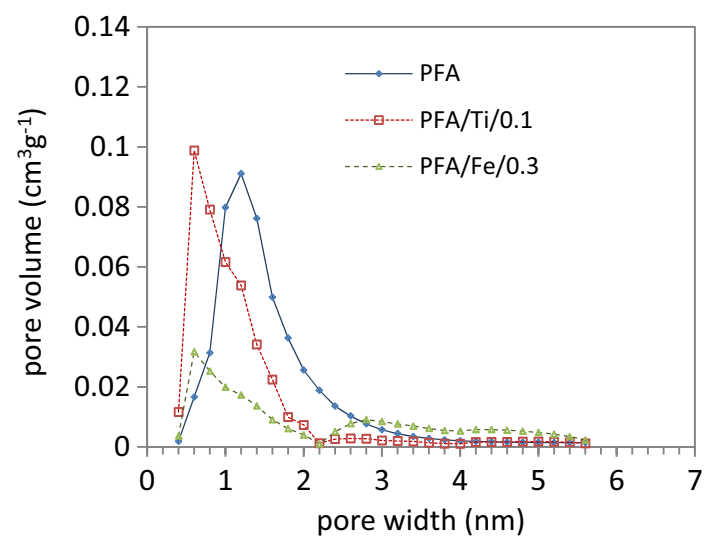

Fig. 4 Micropore size distribution determined by DFT method

both metal-loaded ACs, nevertheless the heteroatom content is still low. The low heteroatom amount results in low number of surface functional groups formed on the carbon surface that is expressed by the value of pHPZC. Carbons selected for adsorption have neutral surface characteristics. The value of pHPZC is very similar and changes between 7.35 and 7.8. In our earlier work, we have shown that in the case of phenol adsorption a crucial role is played by micropore with size smaller than $1.4 \mathrm{~nm}[33,34]$. Hence the pore size distribution (PSD) determined in terms of microporosity by DFT method is given in Fig. 4, whereas the PSD in terms of mesoporosity, calculated on the basis of the Kelvin model, is given in Table 3. It can be seen that the PSD of the selected ACs varies significantly. The PFA and PFA/Ti/0.1, assigned as microporous, are characterized by completely different micropore distribution. The PFA has the maximum of micropore at $1.2 \mathrm{~nm}$, whereas in the case of PFA/Ti it is shifted to ultra-micropores. The maximum is observed at $0.6 \mathrm{~nm}$. Similarly, the PFA/Fe/0.3 has its maximum at $0.6 \mathrm{~nm}$, however the volume of micropores is few folders smaller. Nevertheless, that ACs are characterized by a larger volume of mesopores, especially pores bigger than $10 \mathrm{~nm}$ (Table 3).

\section{Removal of phenol and Congo red}

The adsorption tests were carried out in static conditions at ambient temperature. The same carbon particle size
$(0.2-0.5 \mathrm{~mm})$ and the same shaking speed were used. The $\mathrm{pH}$ of solution was monitored during the test but was not modified.

From the $\mathrm{pH}$ of the solution after adsorption, which ranged from 6.8 to 7.4, it can be inferred that electrostatic forces do not contribute to phenol uptake on PFA-based ACs. Taking into account the $\mathrm{pH}_{\mathrm{PZC}}$ values of ACs (Table 3) and $\mathrm{pK}_{\mathrm{a}}$ of (Table 1), the surface charge of the studied $\mathrm{ACs}$ is around zero, whereas the phenol molecules remain undissociated. In the system CR/PFA-based ACs, despite the occurrence of the $\mathrm{CR}$ molecule in anionic form [pH of solution (Table 3) is higher than $\mathrm{pK}_{\mathrm{a}}$ of CR (Table 1)], no electrostatic forces are expected to appear, due to the fact that the charge on the ACs surface is close to zero too.

In order to determine the equilibrium adsorption isotherm, the equilibrium adsorption time $\left(t_{\mathrm{e}}\right)$ has to be determined. There are a few factors that strongly influence the equilibrium time, i.e., the size of adsorbates and particle size of adsorbent, speed of shaking, and porous texture especially mesopores that act as transporting arteria. Table 4 shows the $t_{\mathrm{e}}$ obtained in this work. It can be seen that $t_{\mathrm{e}}$ changes from 40 to $132 \mathrm{~h}$. As the size of AC particles and speed of shaking is the same for all systems, the differences arise from the two remaining factors. The $\mathrm{CR}$ molecule which is much bigger compared to $P$ requires longer adsorption time to reach the active sites due to steric hindrance. The equilibrium in the case of phenol is reached after 40-46 h, whereas in the case of CR the time is much longer (100,132 h). It should be also emphasized that the $t_{\mathrm{e}}$ decreases in direction PFA $>$ PFA/ Ti $/ 0.1>\mathrm{PFA} / \mathrm{Fe} / 0.3$ for both $\mathrm{CR}$ and $P$. In this direction the mesopore volume decreases hence the smaller the mesopore volume, the more time it takes to establish the equilibrium.

The equilibrium adsorption isotherms for the $P$ and CR on studied carbons are shown in Fig. 5. As can be seen, all isotherms belong to class $\mathrm{L}$ according to Giles classification [35]. According to Giles the L type of isotherm is connected with flat position of the adsorbate molecule toward the adsorbent surface. The Langmuir adsorption is the monolayer adsorption.

Despite the fact that in literature many different equations are used to interpret the equilibrium adsorption isotherms, usually the Langmuir (Eq. 2) and Freundlich (Eq. 3) models give the best fit [36-42], hence in this work only the two models were used to interpret the data. 
Table 4 Phenol and Congo red adsorption parameters

\begin{tabular}{lllll}
\hline Adsorbate & Adsorbent & & & \\
\cline { 2 - 4 } Congo red & Langmuir & PFA & PFA/Fe/0.3 & PFA/Ti/0.1 \\
& $q_{\max }\left(\mathrm{mg} \mathrm{g}^{-1}\right)$ & & & \\
& $b\left(\mathrm{dm}^{3} \mathrm{~g}^{-1}\right)$ & 64 & 143 & nd \\
& $R^{2}$ & 0.073 & 0.064 & \\
& Freundlich & 0.932 & 0.943 & nd \\
& $R^{2}$ & & & nd \\
& Equilibrium time (h) & 0.923 & 0.958 & $\mathrm{nd}$ \\
& pH of solution after adsorption & 132 & 100 & 100 \\
& Langmuir & $7.4-7.6$ & $7.7-7.8$ & 0.064 \\
& $q_{\text {max }}\left(\mathrm{mg} \mathrm{g}^{-1}\right)$ & & & 0.990 \\
& $b\left(\mathrm{dm}{ }^{3} \mathrm{~g}^{-1}\right)$ & 189 & 58 & \\
& $R^{2}$ & 0.094 & 0.015 & 0.917
\end{tabular}

The Langmuir equation is based on the assumption of a structurally homogeneous adsorbent where all sorption sites are identical and energetically equivalent. The equation is given by (2):

$q_{\mathrm{e}}=\left(b q_{\mathrm{max}} c_{\mathrm{e}}\right) /\left(1+b c_{\mathrm{e}}\right)$,

where $q_{\mathrm{e}}$ is the equilibrium dye concentration on the adsorbent $\left(\mathrm{mg} \mathrm{g}^{-1}\right), c_{\mathrm{e}}$ is the equilibrium dye concentration in solution $\left(\mathrm{mg} \mathrm{dm}^{-3}\right), q_{\max }$ is the monolayer capacity of the adsorbent $\left(\mathrm{mg} \mathrm{g}^{-1}\right)$, and $b$ is the Langmuir adsorption constant $\left(\mathrm{dm}^{3} \mathrm{mg}^{-1}\right)$.

The Freundlich equation is employed to describe heterogeneous system characterized by the heterogeneity factor of $1 / n$. This model describes reversible adsorption and is not restricted to the formation of the monolayer. It is given by Eq. (3):

$q_{\mathrm{e}}=K_{\mathrm{f}} c_{\mathrm{e}} n^{-1}$,

where $q_{\mathrm{e}}$ and $c_{\mathrm{e}}$ are the dye concentrations on adsorbent $\left(\mathrm{mg} \mathrm{g}^{-1}\right)$ and in solution $\left(\mathrm{mg} \mathrm{dm}^{-3}\right)$, respectively, $K_{\mathrm{f}}$ is the Freundlich constant $\left(\mathrm{dm}^{3} \mathrm{~g}^{-1}\right)$, and $n^{-1}$ is the heterogeneity factor.

The calculated values of the Langmuir and Freundlich equations parameters are given in Table 4 . It can be deduced from the comparison of correlation coefficients $\left(R^{2}\right)$, that the Langmuir model yields a better fit than the Freundlich one. The amount of phenol adsorbed is at average and vary between 58 and $189 \mathrm{mg} \mathrm{g}^{-1}$ whereas the amount of Congo red adsorbed is very satisfactory and changes from 68 to $143 \mathrm{mg} \mathrm{g}^{-1}$. The adsorption capacity toward $\mathrm{P}$ changes in direction PFA $>\mathrm{PFA} / \mathrm{Ti} / 0.1>\mathrm{PFA} / \mathrm{Fe} / 0.3$. It should be emphasized that the PFA and PFA/Ti/0.1 despite similar micropore volume are characterized by significantly different $q_{\max }$.

In many works it is said that the adsorption capacity is strongly dependent on the pore size of adsorbent, but no details on the relationship between the adsorption capacity and pore volume are usually given [43-46]. There are only few works on this subject. For example, it has been shown that the adsorption of trichloroethane and methyl tertiarybutyl ether takes place in micropores about 1.3-1.8 times larger in size than the kinetics diameter of the target adsorbates [47]. Also the adsorption of 4,6-dimethyldibenzothiophene (DMDBT) was found to be governed by pores with a width of less than $1 \mathrm{~nm}$ so that it corresponds to the an approximate DMDBT molecule size [48]. In our earlier studies on the phenol adsorption we have found that the adsorption capacity relies on the volume of pore with size smaller than $1.4 \mathrm{~nm}[33,34,49]$. What is more, for carbons obtained from polymer a lower limit of pore size was also established. Hence due to the fact that there are no electrostatic forces and no functional groups that could influence the adsorption, similar simulation was undertaken in this work. The volume occupied by phenol $\left(V_{\mathrm{P}}\right)$ was calculated on the basis of Langmuir adsorption capacity $\left(q_{\max }\right)$ and was compared with the volume of micropores with defined size. The relationship between selected pore volume and $V p$ is given in Fig. 6a. Again the perfect fit was obtained for correlation $V_{\mathrm{P}}$ and volume of pores with size $0.8-1.4 \mathrm{~nm}$. Moreover, the ratio of $V_{\mathrm{p}} / V_{0.8-1.4}$ was found to be the closest to one $(0.954$, $0.951,0.975)$. These studies support our earlier finding that the phenol adsorption mechanism is based on micropore filling via the $\pi-\pi$ dispersion in pores approximately $1-2$ times larger than the molecular diameter. 

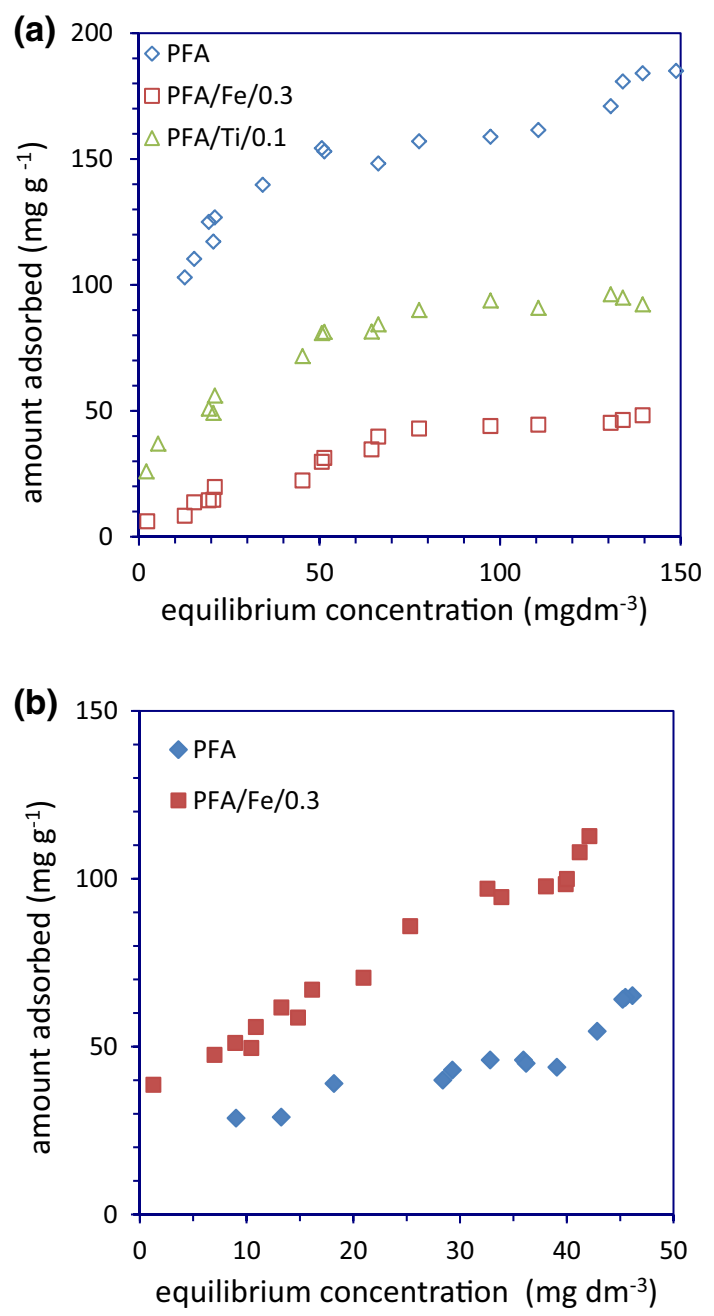

Fig. 5 Equilibrium adsorption isotherms of phenol (a), and Congo red (b) on PFA-based ACs

Also in the case of CR adsorption, there are some studies on the relationship between the adsorption capacity toward CR and volume of pore with defined size. For example, Krupa and Cannon [50] found that the CR adsorption on ACs is related to adsorption in pores size from 1.4 to $47.5 \mathrm{~nm}$, whereas Kasaoka et al. [51] claimed that the critical adsorption pore size for CR was $2.26 \mathrm{~nm}$. On the contrary, Pelecani and Snoeyink [52] in theirs work on $\mathrm{CR}$ adsorption on activated carbon fibers have shown a very good correlation of volume of CR adsorbed and volume of pores with size $0.8-0.95 \mathrm{~nm}$. The discrepancy between the sizes of pores that are believed to be the target is significant. Taking into account the molecular volume of CR (Table 1), the volume of adsorbed dye $\left(V_{\mathrm{CR}}\right)$ was calculated. Next, similarly to studies given for phenol, the $V_{\mathrm{CR}}$ versus volume of pores with different sizes was compared. Special attention was given to pore with size
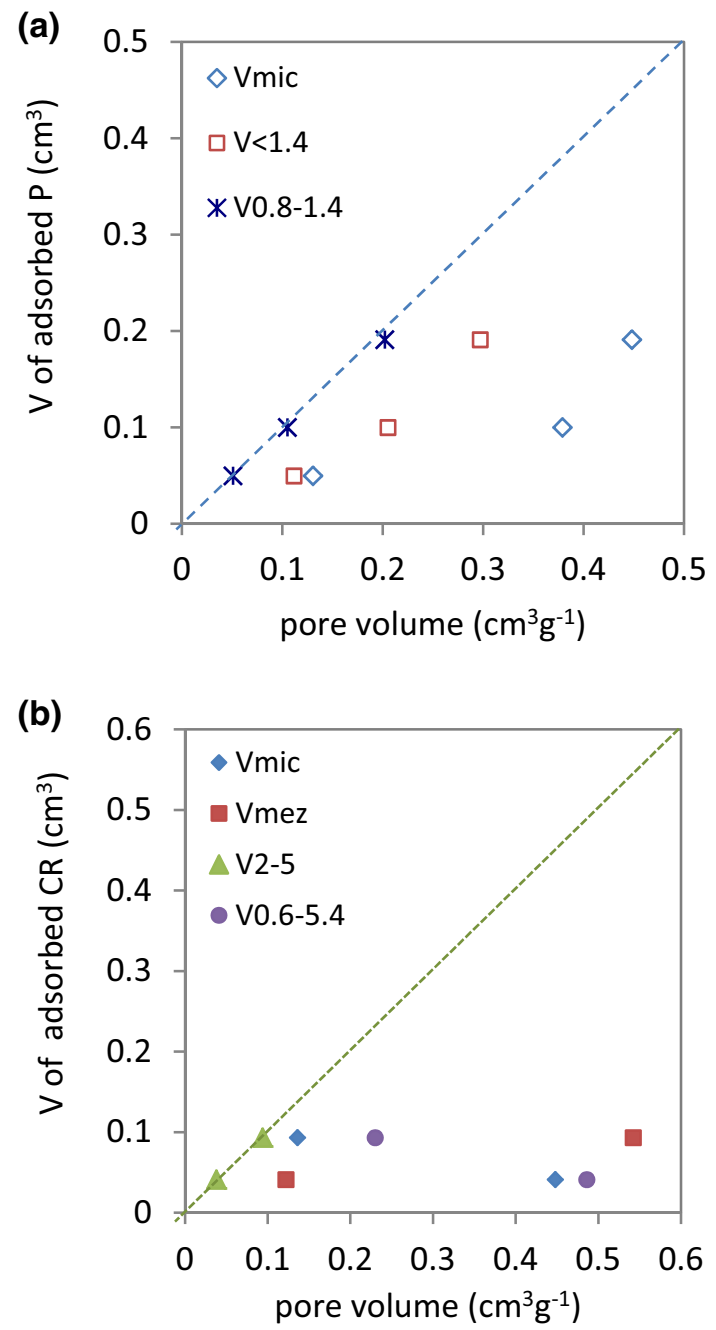

Fig. 6 Correlation between the volume of pores of different sizes and the volume of adsorbed phenol (a), Congo red (b)

1-2 times larger than the molecular dimension of $\mathrm{CR}$, i.e., $0.6-5.4 \mathrm{~nm}$. The ratio of $V_{\mathrm{CR}} / V_{\text {pore }}$ changes from 0.128 for $V_{\mathrm{CR}} / V_{0.6-5.4}$ to 1.08 for $V_{\mathrm{CR}} / V_{2-5}$. It can be seen that the ratio closest to 1 was found for the volume of pore with size $2-5 \mathrm{~nm}$ for both studied ACs. Figure $6 \mathrm{~b}$ shows that the volume of pore with width $2-5 \mathrm{~nm}$ is almost the same as the volume of CR adsorbed. So similarly to the observation given by Kasaoka [47] the lowest pore limit determined by the molecular sieve effect is around $2 \mathrm{~nm}$, whereas the largest pore size limit that is decided by the maximum adsorption forces arising from the overlapping potential of opposite pore walls is $5 \mathrm{~nm}$. Hence, it can be summarized that in the case of big molecules with three molecular dimensions, the two with the large width are the limiting factors since they define the border of steric hindrance in pores. 


\section{Conclusions}

The process of conversion of polymer into an activated carbon is very convenient and environmentally friendly method of reusing the waste. This work shows that presence of iron significantly increases the reactivity of polymer toward the gasification processes that reduces the time and energy. Additionally, iron was proved to be a very efficient catalyst for the mesopore formation during catalytic gasification of PFA. The extent of the mesoporosity development was strongly related to Fe concentration. The optimum Fe content in PFA for the mesopore formation was found to be $0.3 \mathrm{wt} \%$. The higher the Fe content, the mesoporosity extent was slightly lower.

The PFA was found to be a very promising material for production of activated carbon with neutral surface characteristics and tailored porous texture. Moreover, this work shows that the adsorption is related to the volume of pores with defined pore size. In the case of adsorption of small molecules like phenol, the dependency between the adsorption capacity and volume of pore with size $0.8-1.4 \mathrm{~nm}$ is found. In the case of adsorption of Congo red, the relationship with volume of pore with size $2-3 \mathrm{~nm}$ was shown.

Acknowledgements The work was financed by a statutory activity subsidy from the Polish Ministry of Science and Higher Education for the Faculty of Chemistry of Wrocław University of Science and Technology.

Open Access This article is distributed under the terms of the Creative Commons Attribution 4.0 International License (http://creativeco mmons.org/licenses/by/4.0/), which permits unrestricted use, distribution, and reproduction in any medium, provided you give appropriate credit to the original author(s) and the source, provide a link to the Creative Commons license, and indicate if changes were made.

\section{References}

1. Ioannidou O, Zabaniotou A (2007) Agricultural residues as precursors for activated carbon production-a review. Renew Sustain Energy Rev 11:1966-2005

2. Dias JM, Alvim-Ferraz MCM, Almeida MF, Rivera-Ytrilla J, Sanchez-Polo M (2007) Waste materials for activated carbon preparation and its use in aqueous-phase treatment: a review. $\mathrm{J}$ Environ Manag 85:833-846

3. Kawamoto K, Lu B (2016) Gasification and reforming of biomass and waste samples by means of a novel catalyst. J Mater Cycles Waste Manag 18:646-654

4. Radovic LR, Moreno-Castilla C, Rivera-Utrilla J (2001) Carbon materials as adsorbents in aqueous solutions. In: Radovic LR (ed) Chemistry and Physics of Carbon, vol 27. Marcel Dekker, New York, pp 27-405

5. Radovic LR, Rodriguez-Reinoso F,(2001) Carbon materials in catalysis. In: Thrower PA (ed) Chemistry and Physics of Carbon vol 25. Marcel Dekker, New York, pp 243-358
6. Lozano-Castello D, Alcaniz-Monge J, de la Casa-Lillo MA, Cazorla-Amoros D, Linares-Solano A (2002) Advances in the study of methane storage in porous carbonaceous materials. Fuel 81(14):1777-1803

7. Frackowiak E, Beguin F (2001) Carbon materials for the electrochemical storage of energy in capacitors. Carbon 39(6):937-950

8. Burness LT (ed) (2009) Mesoporous materials: properties, preparation and application. Nova Science Publisher, USA

9. Oya A, Yoshida S, Alcaniz-Monge J, Linares-Solano A (1995) Formation of mesopores in phenolic resin-derived carbon fiber by catalytic activation using cobalt. Carbon 33(8):1085-1090

10. Oya A, Yoshida S, Alcaniz-Monge J, Linares-Solano A (1996) Preparation and properties of an antibacterial activated carbon fiber containing mesopores. Carbon 34(1):53-57

11. Tamai H, Kakii T, Hirota Y, Kumamoto T, Yasuda H (1996) Synthesis of extremely large mesoporous activated carbon and its unique adsorption for giant molecules. Chem Mater 8(2):454-462

12. Yoshizawa N, Yamada Y, Furuta T, Shiraishi M, Kojima S, Tamai H, Yasuda H (1997) Coal-based activated carbons prepared with organometallics and their mesoporous structure. Energy Fuels 11(2):327-330

13. Liu Z, Ling L, Qiao W, Wu D, Liu L (1999) Effects of various metals and their loading methods on the mesopore formation in pitch-based spherical activated carbons. Carbon 37(8):1333-1335

14. Lorenc-Grabowska E, Gryglewicz G, Gryglewicz S (2004) Development of mesoporosity in activated carbons via coal modification using $\mathrm{Ca}$ - and Fe-exchange. Microporous Mesoporous Mater 76:193-201

15. Marsh H, Diez MA, Kuo K (1991) Fundamental issues in control of carbon gasification reactivity. Kluwer, Dordrecht

16. Liu Z, Ling L, Qiao W, Liu L (1999) Preparation of pitch-based spherical activated carbon with developed mesopore by the aid of ferrocene. Carbon 37:663-667

17. Marsh H, Kuo K (1989) Introduction to carbon science. In: Marsh $\mathrm{H}$ (ed) Butterwords, London, pp 107-151

18. Liu Z, Ling L, Lu Ch, Liu L, Wu D (2000) Transformation of doped $\mathrm{Fe}$ in pitch sphere in carbonization and activation processes. Fuel 79:1991-1996

19. Ozaki J, Mitsui M, Nishiyama Y (1998) Carbonization of ferrocene containing polymers and their electrochemical properties. Carbon 36:131-135

20. Sekine Y. Fujimoto K (2003) Catalytic degradation of PP with an Fe/activated carbon catalyst. J Mater Cycles Waste Manag 5:107-112

21. Mariwala RK, Foley CH (1994) Evolution of ultramicroporous adsorptive structure in poly(furfuryl alcohol)-derived carbogenic molecular sieves. Ind Eng Chem Eng 33:607-615

22. Burker ChL, Rajagopalan R, Foley HC (2008) Overcoming the barrier to graphitization in a polymer-derived nanoporous carbon. Carbon 46:501-510

23. Burket ChL, Rajagoopalan R, Marencic AP, Dronvajjala K, Foley HC (2006) Genesis of porosity in poly(furfuryl alcohol) derived nanoporous carbon. Carbon 44:2957-2963

24. Moreira RFPM., Rodrigues AE (2001) Polyfurfuryl alcoholderived carbon molecular sieves. Latin Am Appl Res 31:391-396

25. Liu J, Wang H, Hang L (2004) Highly dispersible molecular sieve carbon nanoparticles. Chem Mater 16:4205-4207

26. Alcaniz-Monge J, Lillo-Rodenas MA, Bueno-Lopez A, IllanGomez MJ (2007) The influence of iron chloride addition to the precursor pitch on the formation of activated carbon fibers. Microporous Mesoporous Mater 100:202-209

27. Nozawa OJun-Ichi, Yamada K, Uchiyama K, Yoshimoto Y, Furuichi Y, Yokoyama A, Oya T, Brown A, Cashion LJ JD (2006) Structures, physicochemical properties and oxygen reduction activities of carbons derived from ferrocene-poly(furfuryl alcohol) mixtures. J Appl Electrochem 36(2):239-247 
28. Moreno-Castilla C, Lopez-Ramon MV, Carrasco-Marin F (2000) Changes in surface chemistry of activated carbons by wet oxidation. Carbon 38:1995-2001

29. Rouquerol F, Rouquerol J, Sing K (1999) Adsorption by powders and porous solids. Principles, methodology and applications. Academic Press, London

30. Salame II, Bandosz TJ (2003) Role of surface chemistry in adsorption of phenol on activated carbons. J Colloid Interface Sci 264:307-312

31. Seredych M, Deliyanni E, Bandosz TJ (2010) Role of microporosity and surface chemistry in adsorption of 4,6-dimethyldibenzothiophene on polymer-derived activated carbons. Fuel 89:1499-1507

32. Dąbrowski A, Podkościelny P, Hubicki Z, Barczak M (2005) Adsorption of phenolic compounds by activated carbon-a critical review. Chemosphere 58:1049-1070

33. Lorenc-Grabowska E, Rutkowski P (2014) High basicity adsorbents from solid residue of cellulose and synthetic polymer copyrolysis for phenol removal: kinetics and mechanism. Appl Surf Sci 316:435-442

34. Lorenc-Grabowska E (2016) Effect of micropore size distribution on phenol adsorption on steam activated carbons. Adsorption 22:599-607

35. Giles CH, Smith D, Huitson A (1974) A general treatment and classification of the solute adsorption isotherm. I: theoretical. J Colloid Interface Sci 47:755-765

36. Ahmaruzzaman M, Sharma DK (2005) Adsorption of phenols from wastewater. J Colloid Interface Sci 287:14-24

37. Ma Y, Gao N, Chu W, Li C (2013) Removal of phenol by powdered activated carbon adsorption. Front Environ Sci Eng $7: 158-165$

38. Lorenc-Grabowska E, Gryglewicz G (2007) Adsorption characteristics of Congo red on coal-based mesoporous activated carbons. Dyes Pigm 74:34-40

39. Juang R-S, Tseng R-L, Wu F-C (2001) Role of microporosity of activated carbons on their adsorption abilities for phenols and dyes. Adsorption 7:65-72

40. Habiba U, Siddique TA, Joo TC, Salleh A, Ang BC, Afifia AM (2017) Synthesis of chitosan polyvinyl alcohol zeolite composite for removal of methyl orange, Congo red and chromium(VI) by flocculation adsorption. Carbohyd Polym 157:1568-1576
41. Lei C, Zhu X, Zhu B, Jiang C, Le Y, Yu J (2017) Superb adsorption capacity of hierarchical calcined $\mathrm{Ni} / \mathrm{Mg} / \mathrm{Al}$ layered double hydroxides for Congo red and $\mathrm{Cr}(\mathrm{VI})$ ions. J Hazard Mater 321:801-811

42. Lei C, Pi M, Jiang C, Cheng B, Yu J (2017) Synthesis of hierarchical porous zinc oxide $(\mathrm{ZnO})$ microspheres with highly efficient adsorption of Congo red. J Colloid Interface Sci 490:242-251

43. Daifullah AAM, Girgis BS (1998) Removal of some substituted phenols by activated carbon obtained from agricultural waste. Water Res 32:1169-1177

44. Li D, Li J, Gu Q, Song S, Peng Ch (2016) Co-influence of the pore size of adsorbents and the structure of adsorbates on adsorption id dyes. Desalin Water Treat 57:14686-14695

45. Bjelopavlic M, Newcombe G, Hayes R (1999) Adsorption of NOM onto activated carbon: effect of surface charge, ionic strength, and pore volume distribution. J Colloid Interface Sci 210:271-280

46. Hsieh CT, Teng H (2000) Liquid-phase adsorption of phenol onto activated carbons prepared with different activation levels. J Colloid Interface Sci 230:171-175

47. Li I, Li PL, Quinlivan PA, Knappe DRU (2002) Effects of activated carbon surface chemistry and pore structure on the adsorption of organic contaminants from aqueous solution. Carbon 40:2085-2100

48. Seredych M, Deliyanni E, Bandosz TJ (2010) Role of microporosity and Surface chemistry in adsorption of 4,6-dimethyldibenzothiophene on polymer-derived activated carbons. Fuel 89:1499-1507

49. Lorenc-Grabowska E, Diez MA, Gryglewicz G (2016) Influence of pore size distribution on the adsorption of phenol on PET-based activated carbons. J Colloid Interface Sci 469:205-212

50. Kropa NE, Cannon FS (1996) GAC: pore structure versus dye adsorption. J Am Water Works Assoc 88(6):94-108

51. Kasaoka S, Sakata Y, Tanaka E, Naitoh R (1989) Design of molecular sieve carbon. Studies on the adsorption of various dyes in the liquid phase. Int Chem Eng 29(4):734-742

52. Pelekani C, SnoeyinkVL (2001) A kinetic and equilibrium study of competitive adsorption between atrazine and Congo red dye on activated carbon: the importance of pore size distribution. Carbon 39:25-37 